\title{
The need for personalized resuscitation guidelines in children with congenital heart disease
}

\author{
Aditya K. Kaza, MD
}

\author{
From the Department of Cardiac Surgery, Boston Children's Hospital and Harvard Medical School, Boston, Mass. \\ Disclosures: Author has nothing to disclose with regard to commercial support. \\ Received for publication Oct 18, 2016; accepted for publication Oct 18, 2016; available ahead of print Nov 16, \\ 2016. \\ Address for reprints: Aditya K. Kaza, MD, Department of Cardiac Surgery, Boston Children's Hospital and \\ Harvard Medical School, 300 Longwood Ave, Bader 273, Boston, MA 02115 (E-mail: Aditya.kaza@cardio. \\ chboston.org). \\ J Thorac Cardiovasc Surg 2017; 153:459 \\ $0022-5223 / \$ 36.00$ \\ Copyright (c) 2016 by The American Association for Thoracic Surgery \\ http://dx.doi.org/10.1016/j.jtcvs.2016.10.026
}

The article by Gupta and colleagues ${ }^{1}$ in this issue of the Journal examines the outcomes of children with congenital heart defects after cardiac arrest. Gupta and colleagues ${ }^{1}$ have used Utstein-style guidelines to help determine the outcomes of children who had cardiac arrest occur before or after a cardiac surgical procedure. This singleinstitution study examined the outcomes in 3437 patients during a period of 12 years and included those with congenital heart defects who had undergone at least one cardiac surgical operation or were about to undergo cardiac surgery. The article illustrates the fact that incidence of cardiac arrest in this patient population is not trivial (4.5\%). Constant vigilance is required for the detection of cardiac arrest and for the prompt institution of resuscitative efforts. Most of the arrests $(81.8 \%)$ occurred after the patient had undergone a heart operation. As expected, the rate of cardiac arrest was higher among patients who had undergone a highcomplexity operation. Although most patients survived the arrest event, there was still a significant mortality, noted to be $31.8 \%$ in this study. The focus therefore needs to be on reducing the mortality risk associated with cardiac arrest in this population. Gupta and colleagues ${ }^{1}$ identified other risk factors for mortality after cardiac arrest, including the use of alkalizing agents during resuscitation, use of extracorporeal membrane oxygenation, and longer duration of arrest. These risk factors could represent the higher complexity of disease in these patients.

The take-home message from the article of Gupta and colleagues $^{1}$ is the significant percentage of patients who survived to hospital discharge. It appears that patients with congenital heart disease who have undergone cardiac surgery (or are awaiting heart surgery) and have a cardiac arrest are most likely going to survive this event. The postarrest efforts should focus on prompt institution of resuscitation, with early use of defibrillation when required. The difficulty with this type of analysis is the variable nature of underlying heart defect and surgery. The resuscitative efforts after cardiac arrest in a patient with a shunt who has

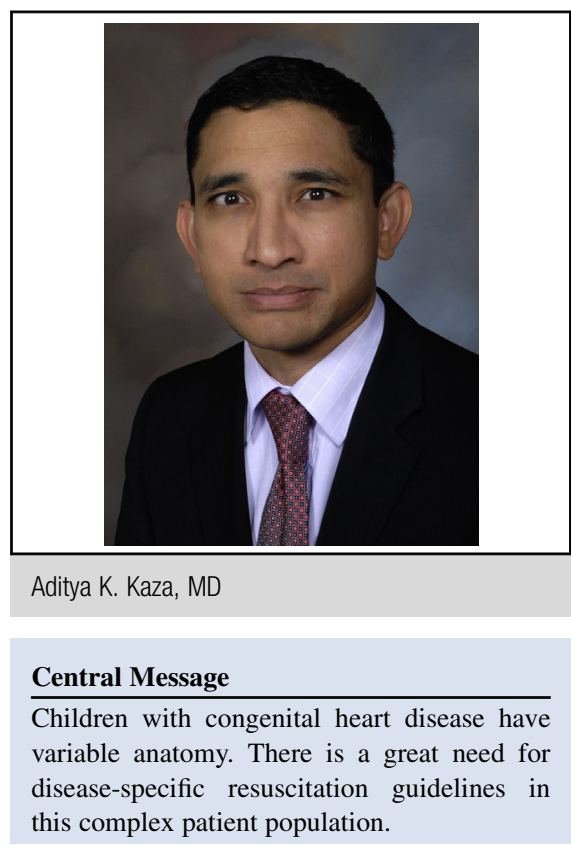

See Article page 450.

shunt thrombosis develop are different from those of a patient with an arrest related to cardiac arrhythmia after repair of tetralogy of Fallot. This study does, however, provide a good framework for the standardization and codification of the resuscitation efforts in patients with congenital heart disease. The efforts also need to be refined according to the disease and specific operation that the patient has undergone. This could be a tedious algorithm, however, considering the variety of congenital heart defects and surgical procedures. Ultimately, it would be helpful to caregivers and potentially would improve patient outcomes if we could develop specific resuscitative guidelines for children with different types of underlying heart disease.

This is one of the first studies to evaluate outcomes after cardiac arrest with standardized guidelines in patients with congenital heart disease either before or after heart surgery. Gupta and colleagues ${ }^{1}$ are to be commended on this effort. This study provides the basis for clinicians in the congenital heart disease field to think about and push for diseasespecific resuscitative guidelines.

\section{Reference}

1. Gupta P, Wilcox A, Noel TR, Gossett JM, Rockett SR, Eble BK, et al. Characterizing cardiac arrest in children undergoing cardiac surgery: a single-center study. J Thorac Cardiovasc Surg. 2017;153:450-8. 